\title{
Economies of Scale in Italian Non-Life Insurance *
}

\author{
by Luigi Prosperetti**
}

\section{Introduction}

As the European market for insurance services becomes gradually unified, the problem of the existence of economies of scale and of their impact on the competitive position of insurance firms, is emerging as one of the major issues, both from the company and the regulatory agency point of view.

Nowhere in Europe this problem is more relevant than in Italy, where the insurance sector has been both strongly sheltered from competition and - until recently - weakly regulated. As a result, the Italian insurance sector has on the whole higher costs than its major European competitors: according to a recent study based on official data, in 1986 the average ratio of costs (excluding claims paid) to direct premium income was $34.9 \%$ in the non-life branches for Italy, against $32.3 \%$ for Germany, $30.1 \%$ for France and $29.1 \%$ for the U. K. ${ }^{1}$

Since Italy also has a very large number of small firms (only 113 of the 239 firms operating in the Italian market in 1988 had premiums above US $\$ 15$ million) an obviously relevant question arises: to what extent the higher costs of Italian insurers should be attributed to a small average firm size?

This paper attempts to answer this question, through an econometric investigation of scale economies in the Italian insurance industry: as the life business is quite young in Italy, and is subjected to the complex regulatory framework briefly outlincd bclow, it seems unlikely that any clear relationship between size and costs could be identificd for this branch: hence, we shall deal here only with the non-life branches, discussing the cxistence of a welldefined relationship between total non-life premiums and total company costs.

Our results will show how cconomies of scale are indeed relevant in the Italian non-life insurance sector, where a company with $\$ 20$ million in premiums should operate roughly

* The author is indebted to the participants of the Seminar of Productivity and Performance in Insurance held at FREF in January, 1990, and to Prof. D. Escher of Assicurazioni Generali for helpful comments on a previous draft of this paper: the author alone remains obviously responsible for the views expressed here. Mr. P. Rossi provided helpful research assistance. Support by the Italian Ministry for University and Research is gratefully acknowledged.

** Professor of Economics and Management, Politecnico di Torino.

1 See Costa (1989). 
with an average cost double than that of a company with $\$ 2$ billion in premiums: as about thirty Italian independent companies fall below the $\$ 20$ million threshold, as competition in the Italian market increases, we should expect widespread restructuring in the Italian insurance industry.

The structure of the paper is as follows: after a brief outline of the main differences between the size and the structure of the Italian market and that of the major European economies (Section 2), in the third section we briefly review a number of theoretical and measurement problems that arisc with the econometric estimation of cost curves for insurance companies: the fourth section presents then a graphical analysis of cost data for a large sample of ltalian companies, and the fifth provides the results of our econometric analysis. The last section brings out the implications of our results for firm strategy and regulatory action in the Italian market.

\section{An outline of the Italian insurance market}

Italy has a rather small insurance market: according to Sigma estimates, in 1987 premium income for all branches was about 19.7 billion dollars for Italy, i. e. less than a quarter than in Germany ( 81.3 billion), less than a third than in Britain ( 63.8 billion), and about two-fifths of the French market ( 50 billion). In terms of total per-capita premiums Italy managed only the 20 th place in a worldwide ranking in 1987 , and was only $33 \mathrm{~d}$ in terms of the share of total premiums in GDP.

The degree of underdevelopment of the Italian market is considerably higher in the life segment, where compulsory public schemes have left only little room, until recently, to private pension schemes: even after double-digit growth rates since 1984, in 1987 Italy had only 74.4 dollars of life premiums per head of population, while Britain had 706, Germany 595 and France 382.

But also the non-life segment of the market is small in an international comparison: here premiums per head in 1987 were 270 dollars in Italy against 416 in Britain, 735 in Germany and 517 in France. Moreover, the weight of motor insurance is considerably higher in Italy than in other countries: 1986 data show that they accounted for $47.6 \%$ of direct premiums in the non-life segment, while this figure was only $36.2 \%$ for Germany, and $40 \%$ for France.

The Italian market is thus seen to be rather small, and with a large component of motor-related insurance, which provides a low (and indeed frequently a negative) margin.

Looking at the structure of supply, Italy has a smaller number of firms (218 in 1986) than Britain (841), Germany (738) or France (558). As the difference in the number of insurance companies is large compared to that in total premiums, prima facie the average size of Italian firms seems to be more in line with that of the other countries considered: in 1986, according to estimates by Assicurazioni Generali, Italian companies had on average a total gross premium income of 82 million dollars, against 97 for Germany, 80 for France and 63 for Britain.

We obtain a similar picture looking at the market share data published by Sigma (1989) for the 15 largest companies in each country: in the non-life segment (table 1) cumulative market shares are quite similar between Italy and France, which both show a higher level of 
Table 1

Cumulated Market Shares in Non-Life Business - 1987

\begin{tabular}{llllll}
\hline & First 3 & First 5 & First 10 & First 15 & $\begin{array}{l}\text { Other } \\
\text { companies }\end{array}$ \\
\hline Germany & 18,3 & 24,6 & 36,7 & 46,6 & 53.4 \\
Great Britain & 37,5 & 54,9 & 72,5 & 78,8 & 21,2 \\
France & 22,2 & 31,7 & 47,6 & 59,9 & 40,1 \\
Italy & 22,7 & 32,9 & 48,0 & 56,4 & 43,6 \\
\hline
\end{tabular}

Source: Sigma, n. 2/89.

concentration than Germany but a lower level than Britain. The picuture is different in the life segment (table 2), but this is partly the artifact of the law requiring all private life insurers to reinsure a fraction of between $10 \%$ and $30 \%$ of new policies written with INA, the state-owned insurance company.

Table 2

Cumulated Market Shares in Life Business - 1987

\begin{tabular}{llllll}
\hline & First 3 & First 5 & First 10 & First 15 & $\begin{array}{l}\text { Other } \\
\text { companies }\end{array}$ \\
\hline Germany & 26,3 & 33,9 & 48,5 & 59,7 & 40,3 \\
Great Britain & 23,5 & 32,0 & 47,0 & 59,0 & 41,0 \\
France & 38,9 & 50,8 & 66,1 & 74,6 & 25,4 \\
Italy & 51,2 & 65,0 & 78,2 & 85,3 & 14,7 \\
\hline
\end{tabular}

Source: Sigma, n. 2/89.

Italy, however, seems to have a longer 'tail' in the size distribution of firms, as we can see from a comparison of the two markets that were found to be rather similar: Italy and France. $^{2}$

The largest Italian firm in 1988 had about 1.8 billion dollars of direct non-life premiums in the national market, while the largest French firm had about 2.5. This gap holds for the top twenty companies in the two countries; it is then reduced up to the 70th position and then grows again rapidly, becoming extremely large towards the bottom of the distribution: the 150th Italian firm had in 1988 premiums of 800.000 dollars while the 150th French was more than nine times larger, reaching 7.5 million dollars of premiums.

Italy, therefore, has a large number of firms active in the non-life branches, and a large portion of them are indeed micro-firms.

\footnotetext{
${ }^{2}$ Data for this comparison were taken from II Mondo (1989) and l'Argus (1989).
} 
Figure 1:

Direct premiums and average cost for a sample of Italian firms in 1988

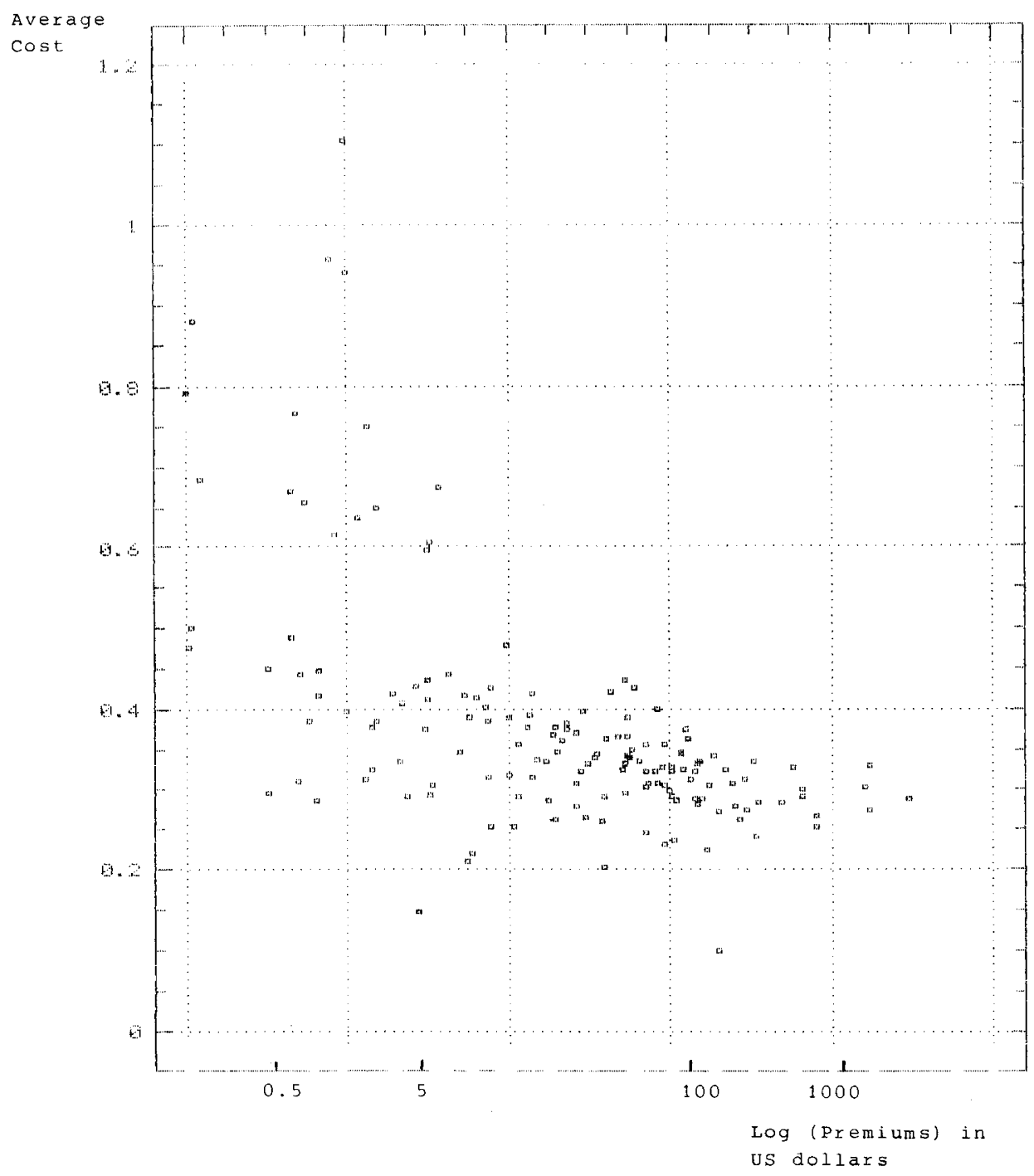


Cost conditions differ widely among these firms, as we can gather from figure 1, which plots average cost - defined as the ratio of total commission and other expenses, including liquidation costs but excluding claims paid, to direct premium income - against dircet premium income for a sample of 151 companies in 1988.

The dispersion in cost conditions is indeed very large: the highest-cost producer has costs as high as $110 \%$ of premiums, while the lowest-cost company has costs as low as $10 \%$ : while some of the variance may be spurious (i. e. due to newly-born companies, captive companics or companies belonging to groups) it sccms clcar from the figure that the cost profile of Italian insurance firms varics grcatly and, furthermore, that larger firms tend to cnjoy lower costs than small firms.

To establish firmly this point, however, we need to analyse the cost-size relationship in a multivariate framework, taking into account the effect of a number of other variables, unrelated to size but likely to have an cffect on the cost Icvel of some companies, such as the degree of specialisation in some specific branches or the type of distribution channels adopted.

However, the econometric estimation of cost curves for insurance companies gives rise to a number of problems, some of which are not met in manufacturing sectors: it seems therefore appropriate to provide a brief methodological discussion before presenting our results in section 4 .

\section{Scale effects in insurance: definition and measurement problems}

The analysis of the relationship between the scale of operations and average costs is more complicated in insurance than in other industrial and service sectors, for two major reasons.

Firstly, it is not immediately clear whether one should try to identify the economic effects on an insurance firm which may be connected to size by looking only (or at any rate, by looking in the first place) to average costs.

Although this is obviously correct in the case of a manufacturing firm, the nature of the insurance business provides companies with extremely large cash balances that are invested in a number of assets, generating a substantial income. This income is usually very large compared with the result of the underwriting activities of the insurance firm, which indeed often turns out to be negative.

If capital markets are not perfect, a large insurance company may be able to obtain a higher return than a small one, but if we look only at cost data provided by the income statement, we would entircly miss any such effect.

To our knowledge, this point has not been so far the object of any applied research: therefore, it seems better to set it aside for future research, and to limit ourselves to a discussion of the traditional cost/size relationship.

The sccond difficulty we meet when analysing the effect of scale in insurance companies is the very definition of scale one should adopt. 
Although the majority of empirical studies have so far adopted premium income as the relevant output measure ${ }^{3}$, this choice gives rise to a number of problems:

a) as Doherty (1981) pointed out, it is not consistent with the economic view of the insurance company as a supplier of contingent claims: under this view, claims paid would provide a better measure of scale, being an ex-post proxy for the true output measure, i. e. the expected value of claims paid;

b) it may entail a simultancity bias in the equation, as premiums are made up of expected claims plus profit and costs, which may lead to a downward bias on the coefficient of premiums in the cost function, and thus to an understatement of the importance of scale economies (sce Skogh, 1982 and 1986).

Gechan (1977) and Braeutigam and Pauly (1986) have pointed out further econometric pitfalls encountered when making use of premiums.

On empirical grounds, the case for making use of claims seems however weaker: if the speed in settling claims is a non-price competitive variable for the insurance firms, as indeed we should expect to happen in the insurance market, ex-post claims could provide a distorted measure of true output. A further distorsion could arise - as pointed out by Johnson et al. (1987) - from the standard practice within the insurance industry of including loss adjustment expenses, often rather crudely estimated, in total claims paid.

Therefore, we will here adopt the standard approach of measuring insurance firms output with total direct premiums.

\section{Econometric analysis of cost curves}

The cost curve that was estimated is derived by a very simple Cobb Douglas model, where a number of firm characteristics are accounted for by linear addition of variables, i.e. :

$$
\log c_{i}=a+b \log \operatorname{PREM}_{i}+c_{l} x_{l}+\ldots+c_{n} x_{n}+\ldots+e_{i}
$$

where $C$ are total costs, defined as the sum of commissions, other expenses (including overheads) and liquidation costs (but excluding claims paid); PREM is direct premium income, and the variables $x_{1} \ldots x_{n}$ are specified as follows:

- DIST is a measure of the cost structure of the distribution system adopted by each company, defined as the ratio of commissions to total costs, so that the variable is close to one for a company that relies heavily on an independent distribution network: if independent agents cost less per unit of premiums sold than company employees, the coefficient of this variable should be negative.

It was also thought useful to test for a systematic effect on cost of a specialisation in particular branches, the cost structure of which may be quite different from the average cost

\footnotetext{
3 The original source provided data for 165 companies, but 14 were excluded from the sample either because they were captive companies, or because they had only very recently began doing business: in both cases it was felt that such companies could hardly be helpful to draw a long-run cost curve for the insurance industry.
} 
structure of total non-life business. We included, therefore, among the regressors two variables measuring the incidence on total premiums of premiums written in some branches that on a priori grounds could display peculiar cost structures, i.e.:

- AUTO, for compulsory auto insurance, which should carry a negative sign if the view broadly held in the insurance companies - that unit costs for this branch are higher than average - is correct ;

- TRANS, for other transport-related insurance, for which we would expect a negative sign, since a large portion of policies written in this branch are rather large.

Lastly, we included two dummy variables to account for the fact that companies belonging to groups or to foreign companies could display lower-than-average costs, as some of their administrative and general expenses could be borne by other firms belonging to the same group or by the mother company:

- DFOR, that takes the value one if a company is the Italian branch of a foreign company and zero otherwise;

- DGROUP, that takes the value one if a company belongs to a group of companies (but is not the group leader), and zero otherwise.

A number of variants of the model were estimated on data taken by Il Mondo (1989), referring to balance sheet data for a sample of 151 companies operating in the Italian nonlife branches in 1988.

To avoid the well-known shortcomings of Cobb-Douglas cost functions in coping with economies of scale, the model was estimated on the complete sample and on three subsamples roughly of the same size, which for convenience we may label as:

- very small companies (or micro companies): 54 firms with less than $\$ 1.3$ million of premium income;

- small companies: 43 firms with premium income between $\$ 1.3$ and $\$ 70$ million:

- medium and large companies: 54 firms with premium income above $\$ 70$ million.

Initial estimation of the full model over the complete sample and the three sub-samples yielded the results shown in table 3 .

The model estimated over the full sample is seen to be rather satisfactory, with a Rsquared of 0.992 and a standard error of $16.3 \%$; as firms in the sample are ordered according to their premium income, the Durbin Watson statistics provide a rough measure of specification errors resulting from the omission of some scale-related variables: given its value, this does not seem to be the case here.

Similar overall remarks apply to the three sub-samples, although when the model is estimated on large firms data, our results are seen to be particularly good: for this segment, our model makes on average a standard error of only $8.9 \%$ when forecasting the total cost of an insurance firm, whereas for small firms our average crror is as large as $23.2 \%$ 
Table 3

Regression results for the initial Cobb-Douglas model

\begin{tabular}{lcccc}
\hline & $\begin{array}{c}\text { complete } \\
\text { sample }\end{array}$ & $\begin{array}{c}\text { small } \\
\text { firms }\end{array}$ & $\begin{array}{c}\text { medium } \\
\text { firms }\end{array}$ & $\begin{array}{c}\text { large } \\
\text { firms }\end{array}$ \\
\hline \multirow{3}{*}{ constant } & 0.276 & 0.545 & -0.583 & $-(0.060$ \\
log PREM & $(5.1)$ & $(3)$. & $(-0.3)$ & $(-0.7)$ \\
DIST & 0.948 & 0.924 & 0.984 & 0.982 \\
& $(93.6)$ & $(25.5)$ & $(22.4)$ & $(54.0)$ \\
AUTO & -0.550 & -0.556 & $-0 .(074$ & -0.685 \\
& $(-5.0)$ & $(-2.8)$ & $(-0.3)$ & $(-3.1)$ \\
TRANS & -0.291 & -0.391 & -0.113 & -0.111 \\
& $(-3.9)$ & $(-2.2)$ & $(-0.7)$ & $(-0.9)$ \\
DFOR & -0.253 & -0.185 & -0.218 & -0.583 \\
& $(-3.5)$ & $(-1.5)$ & $(-1.3)$ & $(3.0)$ \\
DGR & 0.004 & 0.002 & 0.017 & -0.038 \\
& $(0.8)$ & $(0.1)$ & $(0.2)$ & $(-0.4)$ \\
RSQ (adj.) & -0.030 & -0.121 & 0.029 & 0.032 \\
Standard error & $(-0.9)$ & $(-1.3)$ & $(0.5)$ & $(1.1)$ \\
Durbin-Watson & 0.992 & 0.942 & 0.931 & 0.988 \\
n & 0.163 & 0.232 & 0.134 & 0.089 \\
& 1.765 & 1.786 & 1.478 & 1.972 \\
& 151 & 54 & 43 & 54 \\
\hline
\end{tabular}

Of the six explanatory variables employed, only DFOR turned out to be uniformly non-significant: thus, specialisation in compulsory automobile and other transport-related insurance, and the distribution channels employed are seen to affect significantly the costs of insurance companies.

After elimination of the non-significant variables in each equation, the estimates presented in table 4 were obtained, which we now turn to discuss.

Firstly, our results clearly indicate the existence of scale economies in the non-life business in Italy: the overall output elasticity of costs is 0.950 for the whole sample; this value is mostly to be attributed to scale effects in very small firms, where the output elasticity of costs falls to 0.915 .

While such a degree of scale economies may seem to be small, it has in fact a large impact, as the ratio of premiums between the largest and the smallest company in the micro-firms sample is approximately 42 , and thus we could expect the smallest company to have an average cost about 3.5 times greater than that of the largest company. 
Table 4

Regression results for the final Cobb-Douglas model

\begin{tabular}{lcccc}
\hline & $\begin{array}{c}\text { complete } \\
\text { sample }\end{array}$ & $\begin{array}{l}\text { small } \\
\text { firms }\end{array}$ & $\begin{array}{c}\text { medium } \\
\text { firms }\end{array}$ & $\begin{array}{c}\text { large } \\
\text { firms }\end{array}$ \\
\hline constant & 0.244 & 0.604 & -0.727 & -0.120 \\
log PREM & $(5.2)$ & $(3.3)$ & $(-1.8)$ & $(-0.6)$ \\
DIST & 0.950 & 0.915 & 0.990 & 0.971 \\
& $(103.2)$ & $(27.4)$ & $(25.5)$ & $(59.9)$ \\
AUTO & -0.558 & -0.573 & - & -0.625 \\
& $(-6.0)$ & $(-3.8)$ & & $(-2.9)$ \\
TRANS & -0.290 & -0.346 & - & - \\
DGR & $(-4.1)$ & $(-2.0)$ & & -0.420 \\
RSQ (adj.) & -0.259 & - & - & $(-5.2)$ \\
Standard error & $(-3.6)$ & & - & - \\
Durbin-Watson & - & -0.133 & & 0.987 \\
n & 0.992 & 0.9444 & 0.940 & 0.089 \\
& 0.162 & 0.228 & 0.125 & 2.024 \\
\hline
\end{tabular}

Scale effects are far less significant for the second sub-sample, where the coefficient of premiums rises to .900 , and the size dispersion is small, but it becomes again of great relevance in the medium-large companies sub-sample, where a coefficient of .971 and a largestto-smallest ratio of 28 lead us to expect the average cost of the smallest company to be about $80 \%$ higher than that of the largest.

The coefficient of the variable DIST, when significant, is around $-0.5:$ since the variable is constructed as the ratio of commissions to total costs, this agrees with the widely-held view that distribution through agents is cheaper than distribution through a salaried workforce. However, as the elasticity of total cost with respect to this variable evaluated at various sample points turns out to be always very close to zero, differences in the marketing system do not seem to be of practical relevance in determining average cost differences among insurance companies in Italy.

A surprising feature of our results is the negative coefficient on the AUTO variable, which implies that compulsory motor insurance should exhibit an average cost lower than that of total non-life business.

Prima facie this would seem to contrast with the evidence provided by company accounts in Italy, which clearly show that motor insurance is a loss-making business, but this is obviously not the case, since our cost measure does not include claims paid: negative 
results in the auto business are indeed the result of a very high loss ratio resulting from stringent rate controls by the Italian Ministry of Industry, rather than of a high expense ratio. In any case, the elasticity of total cost with respect to this variable is also seen to be negligible throughout the sample.

Similar remarks apply to TRANS, the coefficient of which carries a negative sign $(-0.259$ for the complete sample $)$.

Finally, DGR is marginally significant only in the micro-firms group, where it exhibits a sizeable influence on total costs: a very small company belonging to a group should enjoy, other things being equal, an average cost reduction of about $13 \%$.

\section{Conclusions}

Our results clearly show economies of scale to be relevant in the Italian insurance sector, and therefore broadly agree with those obtained for other industrialised countries.

However, while the value of the estimated elasticities is not very different from those that can be found in the literature, the size dispersion of Italian firms doing business in the non-life branches is so large, that the practical relevance of scale economies in Italy is probably far greater than in other countries: a company with $\$ 20$ million of premiums should roughly display an average cost two times larger than that of a company having $\$ 2$ billion of premiums.

As market conditions in Italy become more competitive, we should expect a rather profound restructuring of the insurance industry to take place, which will entail a gradual elimination of the very small companies, and widespread cost reductions in the remaining firms. 


\section{REFERENCES}

L'Argus (1989), L'assurance dommages en 1988, Paris, 1989.

Assicurazione Generali (1989), Industria e assicurazione di fronte al mercato unico, Trieste.

BERNSTEIN, J. and GEEHAN, R. R. (1988), The Insurance Industry in Canada, The Fraser Institute, Vancouver.

BRAEUTIGAM, R. R. and PAULY, M. V. (1986), "Cost Function Estimation and Quality Bias: the Regulated Automobile Insurance Industry", The Rand Journal of Economics, winter.

COSTA, A. (1989), La struttura dei costi delle imprese di assicurazione italiane ed europee: risultati di una analisi empirica, IFA, Milano.

DOHERTY, N. A. (1981), "The Measurement of Output and Economies of Scale in Property-Liability Insurance", Journal of Risk and Insurance, September.

GEEHAN, R. R. (1977), "Returns to Scale in the Life Insurance Industry", The Bell Journal of Economics, autumn.

Il Mondo (1989), Le prime 200 assicurazioni, Rizzoli, Milano.

ISVAP (1989): Istituto per là Vigilianza sulle Assicurazioni Private - Rapporto sull'attività dell' Istituto, Roma.

JOHNSON, J. E., FLANiGAN, G. B. and WEISBART, S. N. (1987), "Returns to Scale in the Property and Liability Insurance Industry", Journal of Risk and Insurance, March.

Sigma (1989), "Insurer's Market Shares in 12 Countries", Economic Studies, n. 2/ 89, Zurich.

SKOGH, G. (1982), "Returns to Scale in the Swedish Property Liability Insurance Industry", Journal of Risk and Insurance, June.

SKOGH, G. (1986), "The regulation of Swedish Insurance Industry", in Finsinger J. and Pauly M. V. (eds.) The Economics of Insurance Regulation, Macmillan, London. 